\title{
Investigating the Types of Motivation of TESL Students in a Higher Education Institute in Malaysia
}

\author{
Mohammad Ali Al-Saggaf ${ }^{1}$, Zur Ain Nabila Binti Rusli ${ }^{1}$ \\ ${ }^{1}$ Management and Science University, Malaysia \\ Corresponding author: Mohammad Ali Al-Saggaf [mohammad_ali@msu.edu.my]
}

\begin{abstract}
The purpose of this study is to investigate the types of motivation of students from a Higher Education Institute, the School of Education and Social Sciences in learning the English language. The research instrument was adapted from Gardner's Attitude/Motivation Test Battery (AMTB). The questionnaire has 28 items 14 items from intrinsic motivation and 14 items from extrinsic motivation. Students from a Higher Education Institute, Shah Alam, Malaysia participated in answering the questionnaire. The findings reveal that the participating students do have a high level of intrinsic motivation and extrinsic motivation, but if to compare between these two types, intrinsic and extrinsic motivation, the Participating students' intrinsic motivation is slightly higher than their level of extrinsic motivation. The researcher concludes that the participating students rely on intrinsic motivation rather than extrinsic motivation.
\end{abstract}

Keywords: TESL; Motivation; Intrinsic; Extrinsic; Second language; learning; English

\section{Introduction}

Motivation plays an important role for people to learn their second language. According to (Gardner, 2010), motivation is the key factor that contributes to success in language learning. Without motivation people or students do not have any purpose to learn languages. Different students have different goals and need to learn the language. Ryan and Deci (1985) introduced a new perspective of motivation known as Self-Determination theory, in which the types of motivation are divided into two parts. Intrinsic and extrinsic motivation. Intrinsic motivation is when a learner learns a new language because they enjoy learning the language and they learn the language for their selfsatisfaction. Learners participate to learn a new language to please themselves. Extrinsic motivation is when learners motivate themselves to learn a new language by external motivation. For instance, learners learn a new language to please their parents by getting a good grade in English. For extrinsic motivation, learners learn the language for eternal rewards or to avoid punishment.

Gill (2002) mentioned that English is a second language in Malaysia and that is why we learn English since primary schools. This study will be conducted in Management and Science University which the language that is used in the University is the English language. According to Gill (2002), 70 percent of materials in higher educations are in English. Both major English students and nonmajor English students have to take basic English subjects in their course. In Malaysia, the English language has been taught as a second language since primary school. Bahasa Malaysia is the main language that is used in Malaysia's education system and the English language is the second most important language in Malaysia. However, not all students practice and use English in real life. There are a lot of studies showing that even though Malaysian students learned English for 11 years in primary and secondary schools most of the tertiary students in IPTA and IPTS are still weak in the English language. 
According to Yvonne and Gurnam (2013), most of the tertiary students were "exposed to formal English to a minimum 11 years of formal education both at primary and secondary schools even after more than 10 years, of learning English in school, a vast majority of Malaysian students in tertiary students, have been unable to gain a good mastery of the language". Yassin and Razak (2017) argued that students tend to get demotivated when they make mistakes because they are scared of making mistakes. That is why it is important for us to know the types of motivation that motivate students in learning the English Language.

The researchers hope this research paper will help future research and people who work in the education industry to learn and know the types of motivation that motivate the students to learn the English language as motivation is one of the main factors that contribute the success in language learning (Gardner, 2010). Educators or future educators need to know the types and the level of motivation of students in learning the English language. Motivation is the most important factor in learning the English language. Without motivation students or learners will be demotivated to learn the English language and the process of the learning process will be slow. The study will be conducted in a Higher Education Institute Shah Alam. The participants are from the School of Education \& Social Sciences which most of the students are majoring in English. This study aims to focus on the types of students' motivation in learning the English Language. This research paper focuses on the intrinsic motivation and extrinsic motivation of students in learning the English Language. For that purpose, the following research questions were postulated.

1. What is the level of students' intrinsic motivation in learning the English Language?

2. What is the level of students' extrinsic motivation in learning the English Language?

3. Which type of students' motivation in learning English has the highest level?

\section{Literature Review}

There are two well-established theories about motivation in language learning. The first theory by Gardner and Lambert (2000) introduced us to two types of motivation in language learning the first one is instrumental motivation and the second one is integrative motivation. Gardner and Lambert (2000) stipulate that instrumental motivation happens when the learners use the target language as an instrument to achieve what they want which this purpose motivates the learners to learn the English language, for example, a learner learns English to communicate with their clients which the learners use the language as an instrument to achieve what they want (they can communicate smoothly with their client). The second type of motivation by Gardner and Lambert is integrative motivation they said that integrative motivation "refers to the learning language to take part in the culture of its people." Which the learners use the language to fit in society and take part in certain cultures.

The second theory introduced by Ryan and Deci (2000) "Self Determination Theory". Different learners do have different types and levels of motivation, Ryan and Deci (2000) categorize the motivation types into three main parts the first one intrinsic motivation, the second one is extrinsic motivation and the last one is amotivation.

\subsection{Theoretical Framework}

This study is based on Self-Determination Theory, with a focus on two main types of motivations in Self-Determination Theory. The founders of this theory are Ryan and Deci (1985). According to Deci (1992) Self- Determination is when a person wants to participate in an activity "with a full sense of wanting, choosing and personal endorsement" This Self- Determination theory focuses on 
what motivates learners in language learning. Intrinsic motivation when students or learners are motivated by the internal factor to learn a new language. Extrinsic is when the students or the learners are motivated by external factors to learn a new language.

\subsection{Main Factor of Learning English Language}

A study conducted by Hussien and Parilah (2014) revealed that the majority of the respondents have high motivation and positive attitudes towards learning the English language. The results also revealed that the highest reason why learners want to learn English is that they believe that English can help them to get a better job. Geddes (2016) and Razak, Yassin, and Maasum (2020) assert that students learn the English language to pass important English examinations (TOEIC, TOEFL, etc.). The researcher mentioned that if to compare intrinsic and extrinsic motivation the results were equal. Also, Mat and Yunus (2014) revealed that the level of extrinsic motivation of the FELDA students are quite high, with $93 \%$ of the students believe that the English language can benefit them in the future to get a better job. The researcher mentioned that the students have positive attitudes towards learning English and the majority of the students were extrinsically motivated in learning the English language.

Interestingly, the findings of Setiyadi, Mahpul, and Wicaksono (2019) concluded that the majority of the students want to learn English based on these three factors, and the first factor they want to "learn English because in this era we all need to learn English". The second factor, the students want to "learn English because they want to have access to a lot of information". The third factor they want to "learn English because they believe English will benefit them to get a good job in the future" and the last factor fourth factor is that the students "learn English because they want to get a good grade". In Hong, and Ganapathy (2017), the researchers recorded the feedback from the students and analyzed data. The findings revealed that $83 \%$ which the majority of these 12 students were instrumentally motivated and the remaining $17 \%$ were integratively motivated in learning the English language. Most of the students think and believe that the English language can help them to get a better job and they believe that English language can benefit them for their future. Furthermore, Reza, (2019) concluded that the majority of the participants rely on extrinsic motivation than intrinsic motivation. According to Khalid, et. al. (2015), low proficiency students in UMK do have a high level of motivation of external factor that motivates them to learn the English language. The external factor had the highest mean score. Similarly, Genc and Aydin (2017) adapted Gardner's Amotivation/ Motivation Test Battery (AMTB). Their results revealed that the students have a positive attitude towards the English language. The researcher compared the students' level of motivation and their courses, for engineering students, the students do have a positive attitude towards English language but they have a low intrinsic level of motivation in learning English language.

Most of these research paper finding was almost similar which most of the students were extrinsically motivated to learn the English language because the students want to "get a good job in the future", "want to prepare for their future career", "English benefits them for their future career". According to Ruth, Samsiah, Hamidah, and Santhna (2009), the majority of Malaysian students generally rely on extrinsic motivation rather than intrinsic motivation. Which she said that "Malaysian students do not perceive the usefulness of learning English as a second language for selfsatisfaction but Malaysian students learn English for the external rewards" which most of the students learn English because they believe the English language can benefit them for their future career. 


\subsection{Gender Difference in Language Learning}

There is always a debate on gender differences in language learning. Geddes (2016) confirms the findings of his study were equal and the majority of both males and females rely on extrinsic motivation in learning the English language. Moreover, Ruth, Samsiah, Hamidah, and Santhna (2009) emphasized that based on gender both males and females were equally and almost the same for intrinsic motivation and extrinsic motivation in studying English Language. The results revealed that the students of both genders are more extrinsically motivated than intrinsically motivated in studying the English language.

\subsection{Intrinsic Motivation}

Youssef (2016) found that the majority of the students were moderately motivated with $67.8 \%$ in their Academic motivation the results also showed that the students were high in their score for intrinsic motivation. Also, the study of Mat, and Yunus (2014) aimed to know the level of motivation for students this study found that a quite number of students do have a strong desire to learn the English language and have a high level of intrinsic motivation. $90 \%$ of the students agreed with the statement of "I wish I were fluent in English", and 63\% of the students agreed with the stamen of "I wish I could speak many languages perfectly" and half of the students $50 \%$ agreed that "English is my favorite subject in school".

Purwanti, and Puspita (2019) aimed to identify students' motivation for learning and students' English proficiency achievement. The instrument for this research paper was a questionnaire. The research design for this research paper was a correlation research design. Which the researcher will correlate between two variables in this research paper. The sampling for this research paper were 77 university students in their fifth semester of English study programs. The results revealed that students do have a high level of motivation. The researcher mentioned that if to compare these two main motivations, extrinsic and intrinsic motivation, the majority of the students have a high level of intrinsic motivation in learning English language with a 3.99 mean compared to extrinsic motivation with 3.20 mean. 71 out of $77(92.2 \%)$ students were intrinsically students and the remaining $6(7.8 \%)$ students were extrinsic students.

\subsection{Extrinsic Motivation}

A case study conducted by Othman, Manap, Ramli, and Kassim (2018) on Afghanistan students in Malaysia on their motivation in English language learning. This research revealed that the majority of the students their level of extrinsic motivation is higher than their intrinsic motivation in learning English language. The results showed that the teaching styles and activities in the classroom are their main motivational factor in learning English language. The researchers conclude that if to compare these two types of motivation average of extrinsic motivation was $75.1 \%$ and the average of students with extrinsic motivation $51.7 \%$ which shows that the students are extrinsically motivated rather than intrinsically motivated.

Zhao, L. (2012) conducted a study about "Investigating Motivation Types and Influences on Motivation: The Case of Chinese Non-English Majors". The results revealed that students do not have a high level of intrinsic motivation to learn English like how the teacher said about their students. The researcher said that the students love English because the students love the challenge 
of learning English and they learned English for the rewards by getting good grades in English. For the extrinsic factor, the results revealed that students and lecturers have different views of "extrinsic motivation". The researcher concludes that the student relies on extrinsic motivation than intrinsic motivation. The students use the language to get what they want to achieve and for the sake of the external rewards. While the results from Kareema (2016). showed that the high ability students and the low ability students are motivated in all four types of motivation intrinsic, extrinsic, instrumental, and integrative motivation but $40 \%$ of high ability students do not agree with some extrinsic factors in learning English language.

\subsection{LEVEL OF MOTIVATION}

Nadarajan (2019) conducted a study on Malaysian undergraduate' motivation. The results revealed that the students with the high extrinsic level and students with intrinsic motivation have the high positive mean score. The researcher mentioned that most of the students with high extrinsic motivation took the course to improve their grades but students with high intrinsic motivation do not think and see that social groups and grades are important. They really enjoyed learning English language. Jain, and Sidhu (2013) also indicated that the students do have high level of motivation to learn English language. Also, Kreishan, and Al-Dhaimat (2013) postulated a significant positive correlation between intrinsic stimulation and knowledge and one type of extrinsic motivation. The researcher concludes that the students do have a high level of motivation in learning the second language and if to compare these two types of motivation, both of the results were equally the same which the students do have a high level of motivation for both types of intrinsic motivation and extrinsic motivation.

The majority of the students think and see the language as a tool for them to use the language to achieve what they want. Most of the learners generally, agreed that they learned English language to "get a good job" "to get good grades". According to Ruth, Samsiah, Hamidah, and Santhna, (2009), Malaysian students generally have a high level of extrinsic motivation which most of the students in Malaysia think that English language is important because they believe that English can benefit them in the future. Some of the findings show that English major students do have a high level of intrinsic motivation to learn English language perhaps because English major students do have the intention and interest to learn the language because they are the ones who choose the major.

Here in Malaysia English plays an important role in the future learner's success, no matter which field or major the students or the learners are coming from. According to Al-Saggaf, Kader, Alias, and Abdul Raof (2020), Malaysian students learn English to graduates from university, students learn English to pass their exams, students learn English to apply jobs and get a better job. Perhaps that is why all the findings from all the previous research papers do have similar results which most of the learners learn English "to get a better job". In this research paper, the researcher will use SelfDetermination theory by Ryan, and Deci (2000) and will focus on two main types of motivation: Intrinsic and Extrinsic Motivation. Which in this research paper the researcher will investigate the types and level of motivation of students' Higher Education Institute in Shah Alam, Malaysia in learning English language. 


\section{Materials and Methods}

\subsection{Research Design}

The research design for this paper is a quantitative method. The quantitative research method will involve numerical and statistic data. The research tool for the quantitative research method is a questionnaire adapted from the Attitude/Motivation Test Battery (AMTB). There are 104 items in the questionnaire. In which later the researchers reduced the number of items to 28 items. All the 28 items are related to the research questions and objectives of this research paper, where 14 items for intrinsic motivation and 14 items for extrinsic motivation.

\subsection{Sample}

The participants of the study are students from School of Education and Social Science at a Higher Education Institute in Shah Alam, Malaysia. only 235 respondents participated in this study to make the sample size at a level of confidence of $95 \%$ and $5 \%$ margin of error. The researchers chose to do convenience sampling for this research paper. The researchers randomized the sample to get a good representation of the population to ensure the convenience sampling method works. Thus, students from different courses were asked to answer the questionnaire on Google Form via a link that is sent to the participants on WhatsApp.

\subsection{Instrument}

The research tool for this research paper is a questionnaire adapted from the Attitude/Motivation Test Battery (AMTB) by Gardner. The original number of items for AMTB is 104 items but the researcher reduced the number to 28 items. The questionnaire has two main sections. In the first section, there are two items for the demographic background. Item 1 Gender and item 2 Course. In the second section of the questionnaire, there are 28 items for section B. The questionnaire uses a 5 pointLikert scale which starts from $1=$ Strongly disagree, $2=$ Disagree, $3=$ Natural, $4=$ Agree, $5=$ Strongly Agree. The researcher made some changes to some questions. The researcher conducted a pilot study for this questionnaire to check the reliability and validity of the questionnaire that has been modified.

\subsection{Pilot Study}

According to Van Teijlingen, E., \& Hundley, V. (2002), "pilot study refers to a mini version of a full-scale study" He added that pilot study is the most important element of a good research design (Edwin, 2002) For this research paper the researcher modified the questionnaire, reduced the number of items and picked only items that are related to research questions and research objective of this research paper. The researcher adapted the questionnaire from the Attitude/Motivation Test Battery (AMTB) and reduces the number of items from 104 items to 28 items. 14 items are Intrinsic Motivation items, and the other 14 items are Extrinsic Motivation items.

The researcher starts the pilot study from 17th April 2020 to 19th April 2020. Thirty-six (36) participants responded and answered the questionnaire. The researchers collected the data from the participants by distributing the Google form link by using WhatsApp as the platform to distribute the questionnaire. After collecting the data, the researchers Transfer all the data in Microsoft Excel to convert all the data in numerical form and used SPSS software 26 to analyze the pilot study. The reliability Cronbach alpha for all thirty (30) items, which included demographic background, is 0.860 . 
Table 1: Reliability of the Instrument

Reliability of the Instrument

$\begin{array}{lll}\text { Cronbach's Alpha } & \text { Cronbach's Alpha Based on Standardized Items } & \text { N of Items } \\ .860 & .879 & 30\end{array}$

\subsection{Procedures and Data Analysis}

After the results of the pilot study achieved the desired levels of reliability and validity for this research, the researchers distributed the questionnaire to the participants. Google Form was used as the format for the questionnaire. The researcher collects data from the participants via a link by using WhatsApp as the platform to distribute the questionnaire. The participants were from the School of Education \& Social Sciences at a Higher Education Institute in Selangor, Malaysia. Participating students come from different backgrounds gender and different courses. The researchers used descriptive statistics and mean scores to analyze the data. All the data has been analyzed using SPSS software.

\section{Results and Discussion}

There were 235 respondents from a Higher education Institute, Shah Alam Students and all the students are bachelor students. The researcher decided to focus on Bachelor students because the level of students from foundation, diploma, and masters are different from Bachelor students. All of the respondents are bachelor students from the faculty of SESS they are from 10 different courses. The researcher distributed the questionnaire through WhatsApp and it is an online survey. All the data were analyzed by Statistical Package for the Social Sciences (SPSS) to get the mean score, frequency, and standard deviation. The researcher used the mean score to measure the level of motivation of the responding students.

\subsection{Demographic Information}

There are two types of gender of the respondents. Female and male. The majority of the respondents are Female, there are 204 (86.80\%) Female and 31 of the respondents are Male (13.20\%) as shown in Figure (1). The main reason why the majority of respondents are female because the faculty of SESS have a huge number of female students compared to male students. The total number of bachelor students that answered this questionnaire is 235 students.

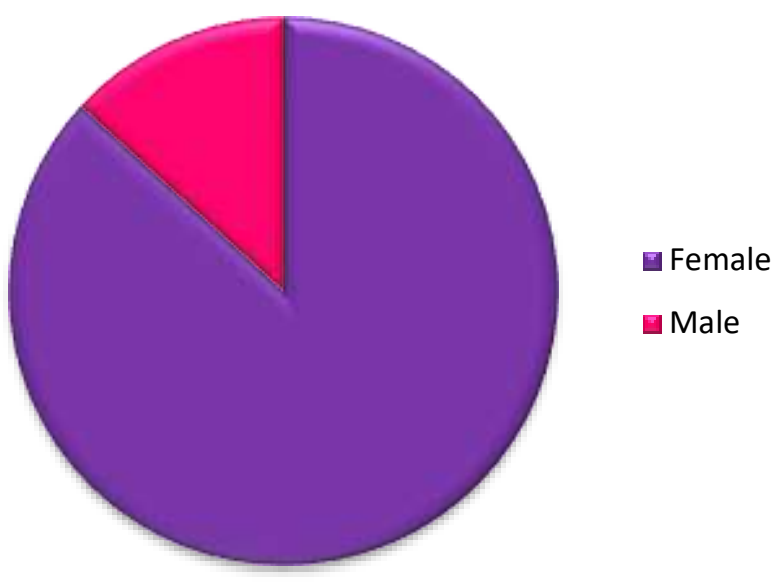

Figure 1. Female/Male Percentage 


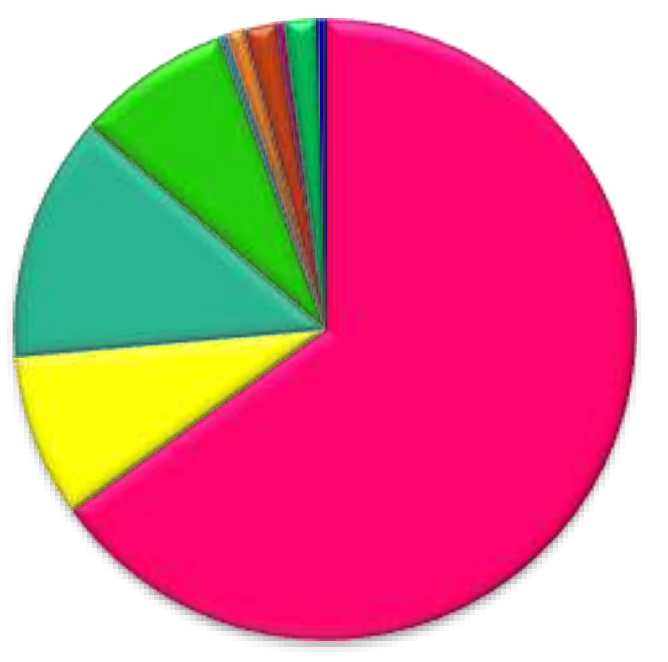

BTESL

$\square \mathrm{BPR}$

$\square B E C E$

$\square$ BELS

$\square B C G$

BE In Visual Art

BE In Physical Education

BE In Science

$\square$ BE In Psychology

BE In Broadcasting

Figure 2. Participants from different Programmes

According to Figure (2), the respondents come from 10 different courses bachelor's in teaching English as a Second Language (BTESL), Bachelor in Public Relations (BPR), Bachelor in Early Childhood Education (BECE), Bachelor in English Literature (BELS), Bachelor in Counseling and Guidance (BCG), Bachelor Education in Visual Art, Bachelor Education in Physical Education, Bachelor Education in Science, Bachelor in Psychology and Bachelor in Broadcasting.

The majority of the respondents that answered the questionnaire are bachelor's in teaching English as a Second Language (BTESL) students which there are 153 students out of 235 students $(65.10 \%)$. 30 students from Bachelor in Early Childhood Education (12.8\%), 20 students from Bachelor in Public Relation (8.50\%), 19 students from Bachelor in English Literature (8.10\%), 4 students from Bachelor in Physical Education (1.7\%), 4 students from Bachelor in Psychology (1.7\%), 2 students from Bachelor Education in Visual Art (0.9\%), 1 student from Bachelor in Counselling and Guidance $(0.4 \%), 1$ student from Bachelor Education Science (0.4\%) and 1 student from Bachelor in Broadcasting (0.4\%). The number of students with bachelor's in teaching English as Second Language is high compared to the other 10 courses because the majority of the populations are from Bachelor in Teaching English as a Second Language.

\subsection{Intrinsic Motivation}

Table 2: Intrensic Motivation Overall

\begin{tabular}{cccccccc}
\hline & Mean & Minimum & Maximum & Range & $\begin{array}{c}\text { Maximum } \\
\text { /Minimum }\end{array}$ & Variance & $\begin{array}{c}\text { No. of } \\
\text { Items }\end{array}$ \\
\hline $\begin{array}{c}\text { Item } \\
\text { Means } \\
\begin{array}{c}\text { Item } \\
\text { Variances }\end{array}\end{array}$ & 4.468 & 4.056 & 4.694 & .639 & 1.158 & .046 & 14 \\
\hline
\end{tabular}

Table 2 shows that the total mean for all the 14 items for intrinsic motivation is 4.468 which very high. It shows that students do have a high level of intrinsic motivation for learning English Language.

Table 3: Intrinsic Motivation Items

\begin{tabular}{|c|c|c|c|}
\hline Item & Mean & $\begin{array}{c}\text { Std. } \\
\text { Deviation }\end{array}$ & $\mathbf{N}$ \\
\hline 1. Learning English is a good self-development & 4.69 & .467 & 36 \\
\hline 2. Learning English will allow me to converse with more varied people & 4.64 & .543 & 36 \\
\hline
\end{tabular}




\begin{tabular}{lccc}
\hline 3. I learn English in order to improve my English language skills & 4.58 & .554 & 36 \\
4. Learning English will allow me to be more at ease with English speaker & 4.58 & .500 & 36 \\
5. Learning English will enable me to be better to understand and appreciate & 4.64 & .543 & 36 \\
English literature & & & \\
6. Learning English allows me to participate more freely in the activities of & 4.58 & .500 & 36 \\
other culture groups & & & \\
7. I learn English because it is something that I always want to do & 4.53 & .696 & 36 \\
8. I study English because I enjoy learning it & 4.61 & .599 & 36 \\
9. I feel more confident in learning English & 4.53 & .774 & 36 \\
10. I make full use of my time to learn English & 4.11 & 1.090 & 36 \\
11. I always look forward to the day when we have English class & 4.06 & .984 & 36 \\
12. I would like to try to use the English which I have learned & 4.50 & .609 & 36 \\
13. I hope we have more English lessons & 4.36 & .723 & 36 \\
14. My English lecturer motivates me to learn English & 4.14 & .961 & 36 \\
\hline
\end{tabular}

Table 3 shows that 3 main items have high mean score the first item is item statement number 1 "Learning English is a good self-development" with a 4.69 mean score, the second highest mean is for item 2 "Learning English will allow me to converse with more varied people" and item statement number 5 "Learning English will enable me to be better understand and appreciate English literature" which both of item got 4.64 mean score and the third highest item is item statement number 8 "I study English because I enjoy learning it" with 4.61 mean score.

\subsection{Extrinsic Motivation}

Table 4: Extrinsic Motivation Overall

\begin{tabular}{cccccccc}
\hline & Mean & Minimum & Maximum & Range & $\begin{array}{c}\text { Maximum/ } \\
\text { Minimum }\end{array}$ & Variance & $\begin{array}{c}\text { No.of } \\
\text { Items }\end{array}$ \\
\hline $\begin{array}{c}\text { Item } \\
\text { Means } \\
\text { Item }\end{array}$ & 3.546 & 2.278 & 4.639 & 2.361 & 2.037 & .646 & 14 \\
Variances & 1.332 & .294 & 2.409 & 2.114 & 8.181 & .516 & 14 \\
\hline
\end{tabular}

Table 4 shows that the mean score of the 14 items for extrinsic motivation is 3.546 which pretty high but if to compare between two categories of motivation intrinsic and extrinsic, participating students rely on Intrinsic motivation more than Extrinsic motivation in learning English language.

Table 5: Mean for Extrinsic Motivation Items

\begin{tabular}{llcc}
\hline Item & Mean & $\begin{array}{c}\text { Std. } \\
\text { Deviation }\end{array}$ & N \\
\hline 15. Learning English is important for my future career & 4.64 & .543 & 36 \\
16. Learning English is useful in getting a good job & 4.58 & .604 & 36 \\
17. I learn English because I need it to further my studies in overseas & 3.97 & .941 & 36 \\
18. I study English because I want to do well in my examination & 4.33 & .717 & 36 \\
19. I need to learn English because it makes me more a knowledgeable person & 4.11 & .950 & 36 \\
20. I learn English because I can contribute more to the society & 4.11 & .887 & 36 \\
21. I need to learn English in order to finish my study & 3.69 & 1.191 & 36 \\
22. Learning English is important for me because other people will respect me \\
more if I am good in English
\end{tabular}




\begin{tabular}{llll}
\hline 26. I will get a better grade if I study English & 3.81 & 1.117 & 36 \\
27. I will be rewarded if I get a good grade in English subject & 3.06 & 1.351 & 36 \\
28. I study English to impress others or to avoid feelings of guilt or Failure & 2.86 & 1.552 & 36 \\
\hline
\end{tabular}

Table 5 shows that the highest level of mean, for extrinsic motivation item is item statement number 15 "Learning English is important for my future career" with a 4.64 mean score followed by the second highest mean score item statement number 16 "Learning English is useful in getting a good job" with 4.58 mean score and the third highest mean score, item statement number 18 ". I study English because I want to do well in my examination" with 4.33 .

\subsection{Comparison of the Mean for Intrinsic and Extrinsic Motivation}

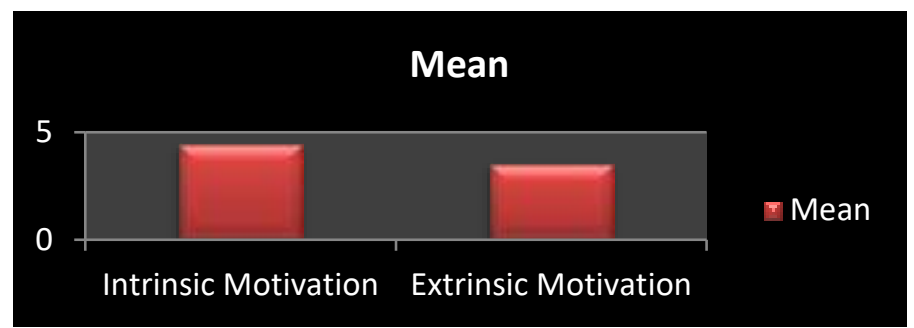

Figure 3. Comparison of the Mean for Intrinsic Motivation and Extrinsic Motivation

\subsection{Levels of intrinsic motivation of students in learning English language}

The first research question was based on the first 14 items in the questionnaire of Attitude/Motivation Test Battery (AMTB) by Gardner. Based on the 14 items statements

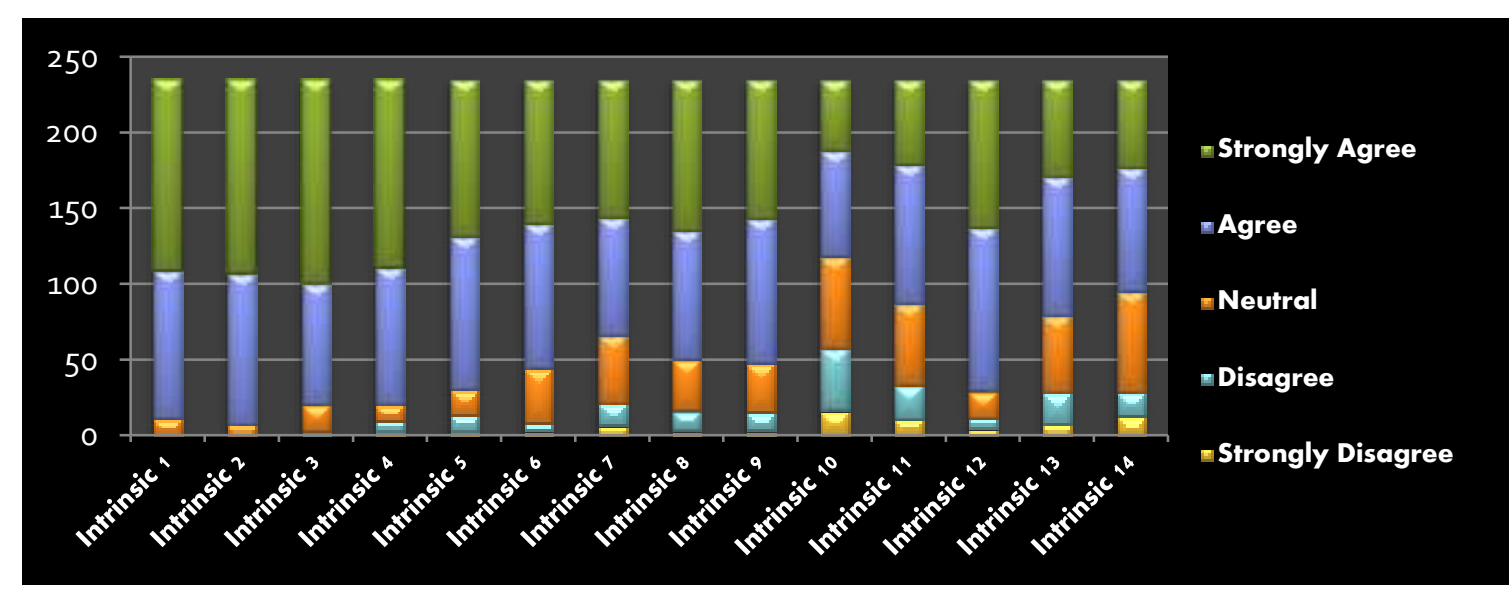

Figure 4. Perception of students' motivation

Figure 4 shows that most of the respondents chose "Strongly Agree" and "Agree" for their item's statements. The top three highest mean scores for intrinsic motivation are item number 1 "Learning English is a good self-development" with a 4.69 mean score.126 out of 235 respondents chose "Strongly Agree" which more than half of the respondents (53.6\%) strongly agree with the statement. I believe that students especially tertiary students do think that English is good for their selfdevelopment because English is the second most important language here in Malaysia. Malaysian students learn English at the primary level, secondary level, tertiary level, and even after they apply for a job. For this item statement, no respondents choose the "Strongly disagree" and "Disagree" option. The second highest mean statement score is, item statement number 2 "Learning English will allow me to converse with more varied people" and item statement number 5 "Learning English will enable me to be better understand and appreciate English literature" which both of item got 4.64 mean 
scores. For item statement number 2, 128 out of 235 respondents chose "strongly agree" and again no respondents choose the "strongly disagree" and "disagree" option. The respondents believe that English can allow them to converse with varied people probably because the English language is a world language and if someone wants to converse with other use English probably because they want to learn the culture or be socialize with others. For item statement number 5, 104 respondents "Strongly agree" with the item statement, which they said that English language enables them to understand and appreciate English literature which this item proves that the respondents willingly to learn English language because they do enjoy learning language and the culture behind the language. The third highest item is item statement number 8 "I study English because I enjoy learning it" with a 4.61 mean score. 100n out 235 respondents "strongly agree" with the item statement. This statement straight shows that a quite number of respondents do enjoy learning English language.

Based on the descriptive statistic mean score, the mean for all 14 items for intrinsic motivation is 4.468 which so high, the results are understandable because the majority of the students in SESS are English majors. According to Huong, 2015 in his study of "A comparison of motivation to learn English between English major and non-English major students" he mentioned that English major students do have a high level of intrinsic motivation than non-English major students.

\subsection{Levels of the extrinsic motivation of students in learning English language}

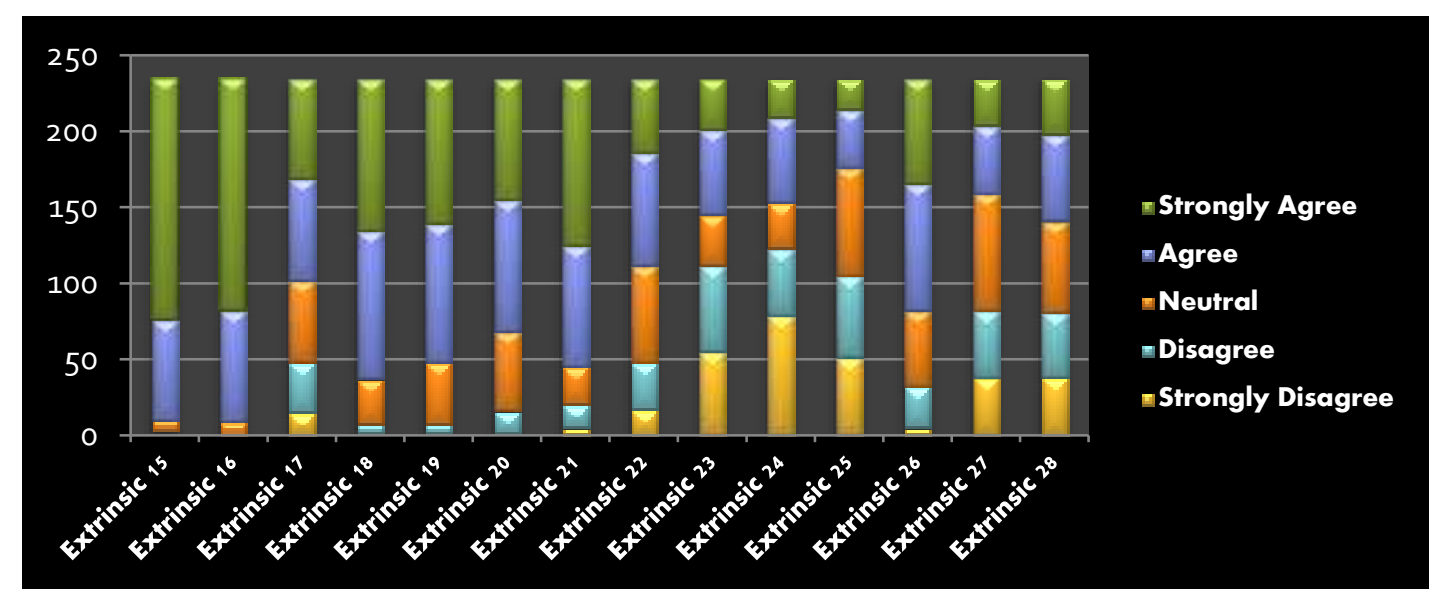

Figure 5. Level of the extrinsic motivation of students in learning English language

Based on Figure, most of the respondents chose "Strongly Agree", "Agree" and "Neutral". The top three highest mean scores for extrinsic motivation are item number 15 "Learning English is important for my future career" with a 4.64 mean score majority of the respondents 159 out of 235 respondents "strongly agree" with the statement, $67.7 \%$. A lot of studies show that the main reason tertiary level students want to learn English because they believe that English language can help them to get a better future. The second highest mean score item statement number 16 "Learning English is useful in getting a good job" with 4.58 mean score, 153 respondents out of 235 respondents "Strongly agree" with the statement, this shows that the tertiary students use English to get a better job, fluency in English is important when the postgraduate students want to apply for a job. It happens in a lot of countries too especially with ESL countries. The students, especially at the tertiary level, use English language as a tool or instrument to get what they want which most of the tertiary students' goals to get a better job. The third highest mean score, item statement number 18 “. I study English because I want to do well in my examination" with 4.33. 100 out of 235 respondents "strongly agree with the statement, again the respondents use English as an instrument to achieve their goals which their goals are to do well in the examination. 
A study conducted by Hussien and Parilah (2014) titled "Motivation and attitude towards Learning English among Undergraduates in National University (UKM)" The findings revealed that the main reason why the students want to learn English because they believe that "English can help them to get a better job" with the highest mean (4.36). This research paper revealed the highest mean of the extrinsic motivation in the questionnaire is "Learning English is important for my future career" with (4.64) mean. Samsiah (2009), the majority of Malaysian students generally rely on extrinsic motivation rather than intrinsic motivation. The findings in this research paper are opposite, it revealed that MSU SESS students have a high level of intrinsic and extrinsic motivation but MSU SESS students rely more on intrinsic motivation rather than extrinsic motivation. The researcher believes that it happened because the majority of the students in SESS faculty major in English. Huong, (2015) English major students rely on intrinsic motivation rather than extrinsic motivation because "English major students have chosen to learn English as their major they may have prepared themselves psychologically and cognitively for their future learning"

\subsection{Types of students' motivation in learning English}

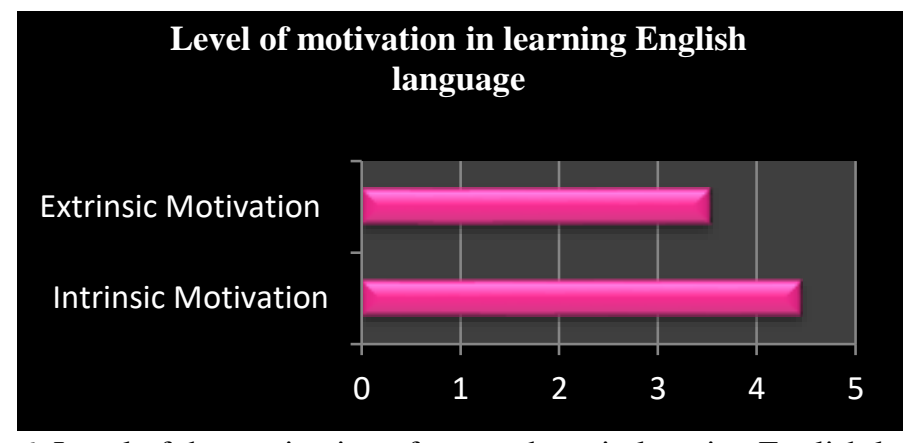

Figure 6. Level of the motivation of respondents in learning English language

For research question number 3, the researcher compares these two types of motivation by mean score. The results showed that participating students do have a high level of both intrinsic motivation and a high level of extrinsic motivation. The researcher uses descriptive statistics and means scores to analyze the data. The researcher compares the mean score between intrinsic and extrinsic mean score it showed that the participating students have a higher level of motivation in intrinsic motivation compare to extrinsic motivation. However, the students do have a high level of extrinsic motivation too.

Table 5: Top 5 items with the highest mean score

\begin{tabular}{clcc}
\hline No. & Items & $\begin{array}{c}\text { Mean } \\
\text { score }\end{array}$ & Type of motivation \\
\hline 1 & Learning English is a good self-development & 4.69 & Intrinsic motivation \\
2 & Learning English will allow me to converse with more varied people & 4.64 & Intrinsic motivation \\
3 & Learning English will enable me to be better understand and & 4.64 & Intrinsic motivation \\
& appreciate English literature & & \\
4 & Learning English is important for my future career & 4.64 & Extrinsic motivation \\
5 & I study English because I enjoy learning it & 4.61 & Intrinsic motivation \\
\hline
\end{tabular}

The findings revealed that most of the high mean scores from intrinsic motivation, there was only 2 item statements from extrinsic motivation. We can conclude that most of the participating students do have a high level of intrinsic motivation. The population for this study probably affects the results too because most of the participating students are English major students. From the intrinsic motivation item statement, most of the students agree with the statement of they do enjoy learning English language or they want to learn English because they want to learn about the culture behind the language. For extrinsic motivation, most of the students use English language as an instrument to 
achieve their goals. Both of the item statements for extrinsic motivation are related to "get a good job" and they believe the English language can help them for their "future career.

The findings revealed that MSU SESS students have high intrinsic motivation and extrinsic motivation, but if to compare between these two types of motivation MSU SESS students have higher intrinsic motivation than extrinsic motivation. The findings were expected because the previous studies conducted by Huong and Rebecca in 2015 titled "A comparison of motivation to learn English between English major and non-English major students in a Vietnamese university" the findings revealed that English major students have a higher level of intrinsic motivation compared to non-English major students. The majority of MSU SESS students are from TESL which most of the students in SESS are major in English.

\section{Conclusion and Implications}

It can be concluded that this study answers all 3 research questions. From the findings, we can conclude that the participating students learn English language because they have a high level of intrinsic motivation to learn the English language. Participating students also do have a high level of extrinsic motivation. For intrinsic motivation, the majority of the students "Strongly agree" with item statement number 1 which they believe that English language can improve themselves and good for self-development. English language is the most used language in Malaysia after the Malay language. For extrinsic motivation, most of the respondents agree with item statement number 15 "Learning English is important for my future career" most of the students believe that English language can help them to get a better future or career. According to Ruth, Samsiah, Hamidah, and Santhna, (2009), she said that majority of Malaysian students are generally relying on extrinsic motivation rather than intrinsic motivation. Based on these findings, the results were the opposite of the statement, probably because the majority of the MSU SESS students are English major students. Huong (2015) stated that English major students rely on intrinsic motivation rather than extrinsic motivation because "English major students have chosen to learn English as their major they may have prepared themselves psychologically and cognitively for their future learning". That is why the findings revealed that MSU SESS students have a higher level of intrinsic motivation compared to extrinsic motivation.

The researchers recommend the future researcher to do stratified random sampling and increase the population, the new research paper should include a variety of faculties in higher education institutes. Secondly, the future researcher can do two instruments, a questionnaire and interview to generalize the findings as a whole. The future researcher can interview lecture instead of focusing on students only.

\section{References}

Abdullah, H. I., \& Shah, P. M. (2014). Motivation and attitudes towards learning English among undergraduates in National University of Malaysia (UKM). International Journal of English and Education, 3(4), 209-227.

Al-Saggaf, M., Kader, F. F., Alias, A. N. I., \& Raof, N. A. A. (2020). Level of Attachment of Malaysian TESL Students Towards Their Cultural Identity. International Journal of Language and Literary Studies, 2(4), 63-82.

Deci, E. L. (1992). The relation of interest to the motivation of behavior: A self-determination theory perspective. The role of interest in learning and development, 44.

Deci, E. L., \& Ryan, R. M. (1985). The general causality orientations scale: Self-determination in personality. Journal of research in personality, 19(2), 109-134. 
Gardner, R. C. (2000). Correlation, causation, motivation, and second language acquisition. Canadian Psychology/Psychologie Canadienne, 41(1), 10.

Gardner, R. C. (2010). Motivation and second language acquisition: The socio-educational model (Vol. 10). Peter Lang.

Geddes, A. J. (2016). Korean University Students' Attitudes and Motivation towards Studying English. Universal Journal of Educational Research, 4(4), 704-715.

Genc, Z. S., \& Aydin, F. (2017). An Analysis of Learners' Motivation and Attitudes toward Learning English Language at Tertiary Level in Turkish EFL Context. English Language Teaching, 10(4), 3544.

Gill, S. K. (2002). Language policy and English language standards in Malaysia: Nationalism versus pragmatism. Journal of Asian Pacific Communication, 12(1), 95-115.

Hong, Y. C., \& Ganapathy, M. (2017). To Investigate ESL Students' Instrumental and Integrative Motivation towards English Language Learning in a Chinese School in Penang: Case Study. English Language Teaching, 10(9), 17-35.

Jain, Y., \& Sidhu, G. K. (2013). Relationship between anxiety, attitude and motivation of tertiary students in learning English as a second language. Procedia-Social and Behavioral Sciences, 90, 114123.

Kareema, M. I. F. (2016). Motivation for learning English among the students of South Eastern University of Sri Lanka.

Kashefian-Naeeini, S., Aminlari, F., \& Mousavi, H. (2018). An investigation into attitudes towards learning English and the motivation type (Integrative vs. Instrumental) in Iranian students at Universiti Kebangsaan Malaysia. International Journal of English Language \& Translation Studies, 6(3), 204213.

Khalid, N. H. A., Hussin, M. W., Ismail, M., Basar, N., Ismail, M. A., Lee, H. S., \& Mohamed, A. (2015). Evaluation of effectiveness of methyl methacrylate as retarder additive in polymer concrete. Construction and Building Materials, 93, 449-456.

Kreishan, L. J., \& Al-Dhaimat, Y. (2013). Intrinsic and Extrinsic Motivation, Orientation and Achievements in L2 of Arab Learners of English, French and German: A Study from Jordan. International Education Studies, 6(12), 52-63.

Mat, S. S. C., \& Yunus, M. M. (2014). Attitudes and motivation towards learning English among FELDA school students. Australian Journal of Basic and Applied Sciences, 8(5), 1-8.

Nadarajan, S. (2019). Malaysian Undergraduates' Motivational Profiles: The Ideal L2 Learners and Motivated Learning Behaviour. Electronic Journal of Foreign Language Teaching, 16(2).

Othman $^{1}$, N. A., Manap, M. R., Ramli, N. F. M., \& Kassim4, A. A. M. (2018). Motivation in English language Learning: A Case Study of Afghanistan Students in Malaysia.

Purwanti, D., \& Puspita, H. (2019). THE CORRELATION BETWEEN ENGLISH LEARNING MOTIVATION AND ENGLISH PROFICIENCY ACHIEVEMENT OF ENGLISH STUDY PROGRAM STUDENTS. Journal of English Education and Teaching, 3(1), 79-94.

Razak, N. A., Yassin, A. A., \& Maasum, T. N. R. T. M. (2020). Formalizing Informal CALL in Learning English Language Skills. In Enhancements and Limitations to ICT-Based Informal Language Learning: Emerging Research and Opportunities (pp. 161-182). IGI Global. 
Ruth, P. R. D., Samsiah, M., Hamidah, H., \& Santhna, L. P. (2009). Workplace Violence Experienced by Nurses in Universiti Kebangsaan Malaysia Medical Centre. Medical and Health, 4(2), 115-121.

Ryan, R. M., \& Deci, E. L. (2000). Intrinsic and extrinsic motivations: Classic definitions and new directions. Contemporary educational psychology, 25(1), 54-67.

Ryan, R. M., \& Deci, E. L. (2000). The darker and brighter sides of human existence: Basic psychological needs as a unifying concept. Psychological inquiry, 11(4), 319-338.

Van Teijlingen, E., \& Hundley, V. (2002). The importance of pilot studies. Nursing Standard (through 2013), 16(40), 33.

Yvonne, J., \& Gurnam K.S. (2013). Relationship between anxiety, attitude and motivation of tertiary students in learning English as a Second Language. Procedia-Social and Behavioral Sciences, 90, 114 $-123$

Yassin, A. A., \& Razak, N. A. (2017). Investigating the relationship between foreign language anxiety in the four skills and year of study among Yemeni University EFL learners. 3L: Language, Linguistics, Literature®, 23(3).

Zhao, L. (2012). Investigation into Motivation Types and Influences on Motivation: The Case of Chinese Non-English Majors. English Language Teaching, 5(3), 100-122. 